\title{
Tropical impact on the East Asian winter monsoon
}

\author{
G. Gollan, ${ }^{1}$ R. J. Greatbatch, ${ }^{1}$ and T. Jung ${ }^{2}$ \\ Received 2 July 2012; revised 23 July 2012; accepted 24 July 2012; published 5 September 2012.
}

[1] The tropical impact on the East Asian winter monsoon (EAWM) is examined in an ensemble of atmospheric general circulation model runs that use relaxation towards the ERA-40 reanalysis in the tropics for winters between 1960/61 and 2001/02 and performed with a recent version of the European Centre for Medium-Range Weather Forecasts model. 25\% of the interannual variance of the EAWM can be reproduced in the ensemble mean by the model experiments with relaxation, even though the influence from ENSO appears to be weak. The implication is that there is the possibility of enhanced predictability for the EAWM resulting from improved forecast skill in the tropics as a whole. Prescribing observed sea surface temperature and sea ice without using relaxation cannot reproduce the interannual variability of the EAWM in our experiments, questioning the usefulness of uncoupled atmosphere models in this region, consistent with previous studies. Citation: Gollan, G., R. J. Greatbatch, and T. Jung (2012), Tropical impact on the East Asian winter monsoon, Geophys. Res. Lett., 39, L17801, doi:10.1029/2012GL052978.

\section{Introduction}

[2] The East Asian winter monsoon (EAWM) is one of the most active components of the climate system in the northern hemisphere extratropical troposphere in winter [Chan and $\mathrm{Li}$, 2004]. It is affected by cold air outbreaks from the region of the Siberian high pressure system and determines the number and the direction of cold surges over eastern and southern China where it impacts local winter climate. The low level northerlies associated with the EAWM are known to influence convection over the South China Sea, over the tropical maritime continent and even to impact the Australian summer monsoon [Zhang and Zhang, 2010]. On the other hand, the El Niño/Southern Oscillation (ENSO) phenomenon is thought to be an important forcing for the Asian monsoon, both during the summer and the winter season [Wang, 2006] as it influences convection over the maritime continent and therefore controls the tropical divergent circulation. Indeed, the interaction between ENSO and the winter monsoon has been found in several studies [Li, 1990; Zhang et al., 1997], El Niño (La Niña) events corresponding to weaker (stronger) winter monsoons. Wang et al. [2008] have also noted a stronger influence of ENSO on the EAWM during the cold phase of the Pacific Decadal Oscillation (PDO) than during

\footnotetext{
${ }^{1}$ GEOMAR | Helmholtz-Zentrum für Ozeanforschung Kiel, Kiel, Germany.

${ }^{2}$ Alfred Wegener Institute for Polar and Marine Research, Bremerhaven, Germany.

Corresponding author: G. Gollan, GEOMAR/Helmholtz-Zentrum für Ozeanforschung Kiel, Düsternbrooker Weg 20, DE-24105 Kiel, Germany. (ggollan@geomar.de)

C2012. American Geophysical Union. All Rights Reserved. 0094-8276/12/2012GL052978
}

the warm phase. Nevertheless, Yang et al. [2002] note that a strong East Asian jet stream (EAJS) is associated with a strengthening of the EAWM, while also noting that the link between the EAJS and ENSO is weak.

[3] The northerly winds of the winter monsoon over East Asia are associated with the climatological pressure gradient between the Siberian high (SH) and the Aleutian low (AL) [Jhun and Lee, 2004]. During the late 1970s atmospheric and oceanic conditions around the North Pacific saw a significant decadal change [e.g., Trenberth and Hurrell, 1994], affecting a number of regional climate patterns. At about the same time, the SH weakened [Gong and Ho, 2002] and the AL became stronger [Trenberth and Hurrell, 1994]. Overall, however, the EAWM intensity was weaker after the climate shift than before (Figures 1a-1c). The forcing of the interdecadal change was attributed to the warming of the tropical oceans [e.g., $H u$, 1997] and a weakening of the EAWM is also expected to continue in the course of further global warming [Hori and Ueda, 2006]. Zhou et al. [2008] show that atmospheric general circulation (AGCM) model experiments forced with observed sea surface temperatures and sea ice (SSTSI) fail to reproduce the interannual variability of global monsoonrelated precipitation over the ocean area, but can reproduce the global precipitation variability over land. These authors can also explain the global weakening trend in the annual precipitation range associated with the global monsoon system during the last half of the 20th century but find the opposite trend to that observed over Eastern Asia.

[4] In this paper we examine the impact of the atmospheric tropical circulation and of observed SSTSI anomalies on the variability of the winter (December/January/February - DJF) mean EAWM over the period 1961 to 2002 (where year 1961 refers to the winter $1960 / 61$ etc.). We use data from the ERA-40 reanalysis and also experiments using the European Centre for Medium-Range Weather Forecasts (ECMWF) model. We find that prescribing the historical evolution of global SSTSI in an AGCM is not sufficient to reproduce the interannual variability of the EAWM but that using relaxation within the tropical atmosphere leads to much better results. Furthermore, we investigate to what extent our forcings can reproduce the weakening trend of the EAWM. The experiments are run for 42 winters from 1960/61 to 2001/02 as in Greatbatch et al. [2012] and are described in section 2.1. Section 2.2 gives an outline of the statistical technique used to analyse the model output and the definitions of the indices used in this study are presented in section 2.3. The results of our model experiments are described in section 3 and a summary and discussion is given in section 4 .

\section{Methods}

\subsection{Model and experimental setup}

[5] The numerical model used for our experiments is a recent version of the ECMWF AGCM (cycle 36R1). The 
EAWM, (a) OBS-NO

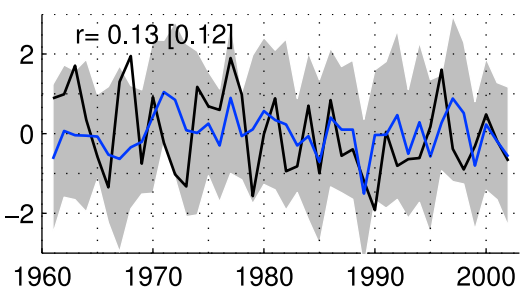

(b) CLIM-TROPICS

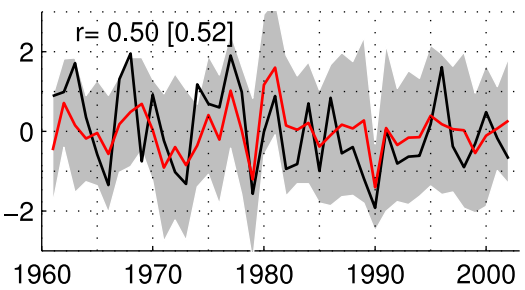

(c) OBS-TROPICS

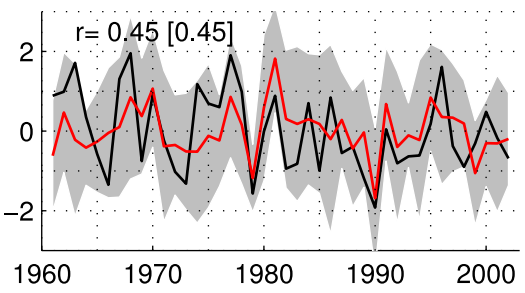

SHCl, (d) OBS-NO

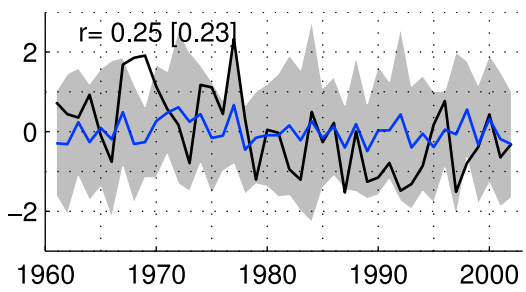

(e) CLIM-TROPICS

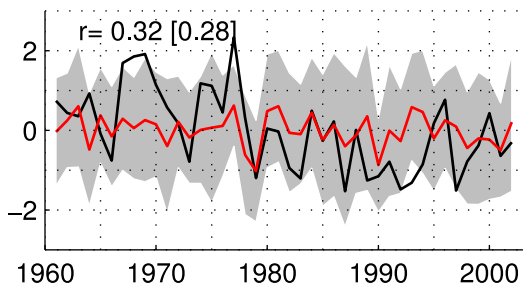

(f) OBS-TROPICS

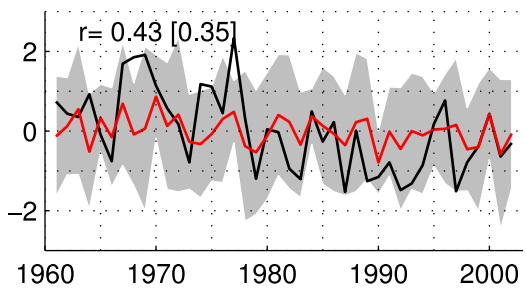

Figure 1. The mean (a, b, c) DJF $E A W M_{S L P}$ indices and (d, e, f) SHCI indices (see section 2.3 for definitions) obtained from the reanalysis data ERA-40 (black indices) and from the ensemble means of the model experiments (blue: without relaxation; red: with relaxation). The grey shadings mark plus/minus two standard deviations of the index values from the ensemble members about the corresponding ensemble means. The correlation between the ensemble mean and the index obtained from the reanalysis is given in the figure (in brackets for the detrended time series).

model was run at a horizontal resolution of T159 with 60 levels in the vertical, the same as used to create the ERA-40 reanalysis data [Uppala et al., 2005], avoiding the need for interpolation when relaxation is applied. The relaxation technique is a method to draw certain parts of the climate model towards a prescribed state which in our case is given by the reanalysis data set ERA-40. In fact, there is an extra term added to the model:

$$
-\lambda\left(x-x_{r e f}\right)
$$

where $x$ represents the model state vector and $x_{\text {ref }}$ is the reference field towards which the model is drawn. The actual parameters directly affected by the relaxation in our case are the horizontal velocity components $\mathrm{u}$ and $\mathrm{v}$, temperature $\mathrm{T}$ and the logarithm of the surface pressure $\ln \left(p_{s}\right) . \lambda=a \lambda_{0}$ defines the strength and region of the relaxation; in our case the timescale of the relaxation is determined by $\lambda_{0}=0.1 \mathrm{~h}^{-1}$. The region given by $a$ defines the tropics as the belt between $20^{\circ} \mathrm{N}$ and $20^{\circ} \mathrm{S}$, with a hyperbolic transition of $20^{\circ}$ width so that $\lambda$ increases from zero to $\lambda_{0}$ from $30^{\circ}$ to $10^{\circ} \mathrm{N} / \mathrm{S}$ (an illustration of the relaxation coefficient can be found in Jung et al. [2010], Figure 1).

[6] The following experiments were performed:

OBS-NO: The relaxation parameter $\lambda$ is zero everywhere, but the model sees the daily evolution of global SSTSI prescribed from the ERA-40 data.
CLIM-TROPICS: Here the relaxation is applied as described above at all model levels, i.e., throughout the depth of the tropical atmosphere. The lower boundary condition is given by the climatological seasonal cycle of SSTSI in ERA-40 obtained from the period 1979 to 2001, when satellite data was available.

OBS-TROPICS: Here the forcings of the former two experiments are combined so that in addition to the relaxation as in CLIM-TROPICS, the evolution of daily SSTSI is prescribed at the lower boundary as in OBS-NO. With tropical relaxation, the effect of specifying SST in the tropics is completely overwhelmed, so that in OBS-TROPICS the additional forcing compared to CLIM-TROPICS is given by the specified extratropical SSTSI.

[7] For each winter and for each experiment, an ensemble of 12 members was integrated. Each of the 12 members was run with a slightly different initial condition taken from the beginning of November before each winter and every integration was started on November 1st. All analysis described in this study is based on anomalies obtained by subtracting the climatology from each field. The climatology was computed separately for each experiment in order to focus on the differences in the dynamics rather than on the climatologies of the different experiments.

[8] The reader is referred to Greatbatch et al. [2012] for more details on the experiments and Hoskins et al. [2012] who give a detailed theoretical discussion of the relaxation method as applied to the tropics. 
Table 1. Interannual Correlations From Reanalysis Data for DJF Means From 1960/61 to 2001/02

\begin{tabular}{|c|c|c|c|c|}
\hline MODE & NINO & SHCI & $E A W M_{S L P}$ & $E A J S_{U 200}$ \\
\hline HCI & $-0.26[-0.30]$ & & & \\
\hline$E A W M_{S L P}$ & $-0.28[-0.29]$ & $0.74 *[0.72 *]$ & & \\
\hline$E A J S_{U 200}$ & $-0.07[-0.07]$ & $0.27[\mathbf{0 . 4 6 *}]$ & $0.61 *[0.72 *]$ & \\
\hline PNA & $0.41^{*}\left[0.41^{*}\right]$ & $0.09[0.19]$ & $0.48^{*}\left[0.56^{*}\right]$ & $0.60 *[0.59$ \\
\hline
\end{tabular}

${ }^{\mathrm{a}}$ The values for detrended time series are shown in brackets. Values exceeding the $95 \%(99 \%)$ confidence level based on a Student's t-test are shown in bold (marked by an asterisk).

\subsection{Monte Carlo experiments}

[9] For each experiment $12 \times 42=504$ realisations are available from which the different indices (e.g., $E A W M_{S L P}$, see below) can be computed. To test the strength of the forcing in each experiment, a large number $(10,000)$ of possible realisations of a particular index is obtained by randomly choosing for each year one of the 12 available index values. Then the correlation is computed between each of the new time series for that index and the time series obtained from the reanalysis. The shift of the resulting probability density function (PDF) away from zero then indicates the strength of the forcing.

[10] In a similar way the influence of a forcing on trends over the whole 42 year period can be tested. Instead of calculating correlations, the linear trends of the different possible realisations are computed to produce histograms of their trends and compare them to the trend from the reanalysis. The extent to which the PDF of trends of each experiment is shifted towards the trend in the reanalysis indicates the influence of the forcing in each experiment on the trend. It is also possible to see whether the trend in the reanalysis is possible within the context of a particular experiment.

\subsection{Indices used in this study}

[11] Apart from the NINO index, all indices below are computed from the ERA-40 reanalysis. The interannual correlations between the time series of DJF means of all indices are listed in Table 1 . In the following the term "significant at the 95\% (99\%) level" refers to the 95\% (99\%) confidence level obtained by a Student's t-test (assuming 42 degrees of freedom and a null-hypothesis of zero correlation) which is reached at a correlation of $r=0.31(r=0.40)$. Assuming 42 degrees of freedom implies that there is only weak autocorrelation, i.e., no memory from one winter to the next, and it should be borne in mind that autocorrelation increases the significance thresholds.

[12] 1. NINO: The DJF mean NINO 3.4 SST index (called NINO index hereafter) as a measure for ENSO is taken from the Web site of the National Center of Atmospheric Research [Trenberth and Stepaniak, 2001]. It is defined as the area average of SST in the eastern tropical Pacific $\left(5^{\circ} \mathrm{S}-5^{\circ} \mathrm{N}\right.$ and $\left.170^{\circ} \mathrm{W}-120^{\circ} \mathrm{W}\right)$ and is used to demonstrate how the EAWM and ENSO are related to each other (see Table 1). ENSO was found to change in the course of the 1976/77 climate shift with more warm events after the shift [e.g., Trenberth et al., 2002].

[13] 2. SHCI: The SH serves as the source of cold air masses which are moved southward by the EAWM and the SH interannual variability in winter is closely (positively) correlated to that of the $E A W M_{S L P}$ (see Table 1). Gong and
Ho [2002] defined the Siberian high central intensity (SHCI) index as the area mean SLP in the region where the surface pressure is generally higher than $1028 \mathrm{hPa}$ in the winter season $\left(40^{\circ}-60^{\circ} \mathrm{N}, 70^{\circ}-120^{\circ} \mathrm{E}\right)$. It is found that the $\mathrm{SH}$ intensity has decreased during recent decades (see Figures 1d-1f), resulting in a negative linear trend in the SHCI index with an amplitude of about $-0.4 \sigma / 10 \mathrm{yr}$ (with $\sigma$ being one standard deviation of the index) between $1960 / 61$ to $2001 / 02$.

[14] 3. $E A W M_{S L P}$ : The $E A W M_{S L P}$ index is defined as the zonal pressure gradient between the eastern flank of the $\mathrm{SH}$ $\left(30^{\circ}-55^{\circ} \mathrm{N}, 100^{\circ}-120^{\circ} \mathrm{E}\right)$ and the western flank of the AL $\left(30^{\circ}-55^{\circ} \mathrm{N}, 150^{\circ}-170^{\circ} \mathrm{E}\right)$ [Chan and $\mathrm{Li}, 2004$ ] which, by geostrophy, is a measure of the strength of the northerly winds associated with the EAWM. The $E A W M_{S L P}$ index is significantly correlated to the SHCI index and also to the Pacific North America pattern index (PNA, see below) which measures the strength of the AL. It is also highly correlated with many of the other EAWM indices listed in Wang and Chen [2010]. The intensity of the EAWM weakened during our analysis period (see Figures 1a-1c) resulting in a negative linear trend [Wang et al., 2009]. Its correlation with the NINO index is negative, but not significantly different from zero at the $95 \%$ level. In the analysis of our model experiments we concentrate on this index as the central indicator for the EAWM and we use the SHCI index to investigate the SH.

[15] 4. $E A J S_{U 200}$ : The EAJS is the upper tropospheric feature of the circulation system in the east Asian region. It is intensified both by the southward spread of the cold air from the $\mathrm{SH}$ region due to the EAWM and by the enhanced Hadley cell circulation due to enhanced convection in the tropics associated to the EAWM [Yang et al., 2002]. The EAJS index is defined as the area average of zonal wind anomalies at $200 \mathrm{hPa}$ within the region $30^{\circ}-35^{\circ} \mathrm{N}$ and $130^{\circ}-160^{\circ} \mathrm{E}$ [Yang et al., 2002] and is significantly correlated with the $E A W M_{S L P}$ index (0.72 for the detrended time series, indicating a close relationship) but there is no correlation to the NINO index, consistent with Yang et al. [2002].

[16] 5. PNA: The strength of the AL is measured by the PNA (SLP) index of Trenberth and Hurrell [1994] which is defined as the negative of the area average of SLP within the region $30^{\circ}-65^{\circ} \mathrm{N}$ and $160^{\circ} \mathrm{E}-140^{\circ} \mathrm{W}$. There is a significant correlation between the PNA index and the $E A W M_{S L P}$ and $E A J S_{U 200}$ indices while the highest correlation is found with the $E A J S_{U 200}$ index, indicating the remote influence of the East Asian jet. There is no significant correlation between the SHCI index and the PNA index, indicating that the variability of the $\mathrm{SH}$ is independent from that of the AL. Furthermore, the PNA is known to be influenced by the tropical Pacific, as can be seen in the significant positive correlation between the PNA index and the NINO index.

\section{Model results}

[17] In Figure 1 the $E A W M_{S L P}$ and the SHCI indices from reanalysis data and the model ensemble means are shown. The grey shading measures the spread of the ensemble members. The $E A W M_{S L P}$ and SHCI indices are all normalized by the standard deviation of the corresponding index from the reanalysis. Similar plots for the PNA index can be found in Greatbatch et al. [2012].

[18] With few exceptions, the $E A W M_{S L P}$ index obtained from the reanalysis lies within the range of the ensemble 
(a) OBS-NO, $\mu=0.06, \sigma=0.14$

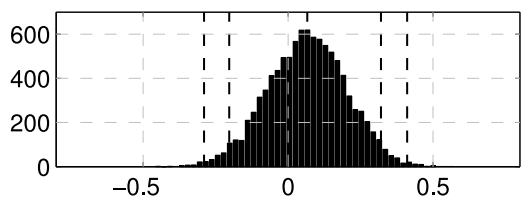

CLIM-TROPICS, $\mu=0.30, \sigma=0.12$

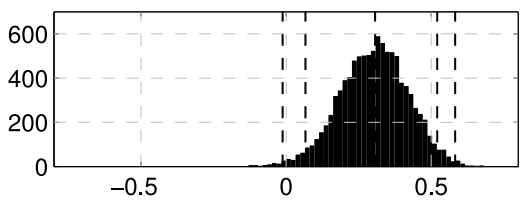

OBS-TROPICS, $\mu=0.29, \sigma=0.12$

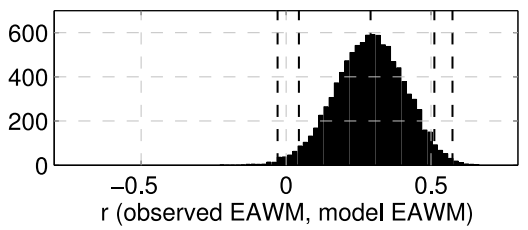

(b) OBS-NO, $\mu=0.10, \sigma=0.14$

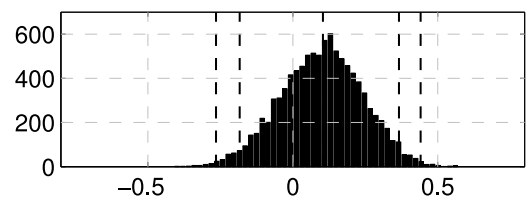

CLIM-TROPICS, $\mu=0.16, \sigma=0.13$

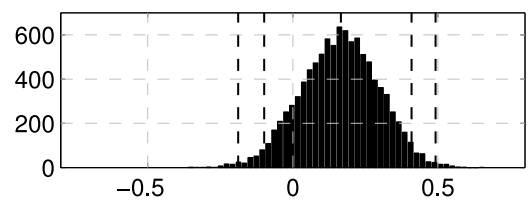

OBS-TROPICS, $\mu=0.20, \sigma=0.13$

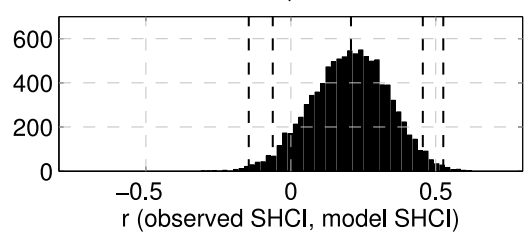

Figure 2. The histograms, using 50 bins, of the correlations $r$ between the (a) $E A W M_{S L P}$ and (b) SHCI indices from 10,000 possible realisations of the model experiments with the corresponding indices from the reanalysis. The dashed vertical lines show the distributions' $95 \%$ and $99 \%$ ranges and the median respectively. The mean $(\mu)$ and the standard deviation $(\sigma)$ of the distributions are given above each panel. For the calculation the time series are not detrended, but the results do not change substantially after detrending.

members of all experiments shown in Figures 1a-1c, indicating that the evolution of the $E A W M_{S L P}$ index in the reanalysis is a possible realisation in our model runs. The amplitude of the ensemble mean time series is, nevertheless, reduced compared to that of the $E A W M_{S L P}$ index from the reanalysis, being highest for OBS-TROPICS. The correlations between the ensemble mean $E A W M_{S L P}$ indices and the index from the reanalysis clearly show the importance of the tropical influence on the northerly winds over Eastern China as they are significantly different from zero at the $99 \%$ level for CLIM-TROPICS and OBS-TROPICS. OBS-NO, on the other hand, yields a low and insignificant correlation between the ensemble mean $E A W M_{S L P}$ index and the corresponding index from the reanalysis.

[19] Figure 2a shows the distributions of correlations between possible realisations from the model experiments and the $E A W M_{S L P}$ index from the reanalysis (see section 2.2). Only for the experiments CLIM-TROPICS and OBSTROPICS is there a strong shift in the distribution to the right, indicative of influence from the imposed forcing. For these two experiments negative correlations lie almost entirely outside the $99 \%$ range of the distributions. The weak performance of OBS-NO in representing the winter monsoon suggests deficiencies in the representation of oceanatmosphere coupling processes at low latitudes in atmospheric models driven by specified SST [see also Copsey et al., 2006]. This is despite including the specified observed interannual variation of SST associated with ENSO as well as the land-sea thermal contrast (thought to be the forcing of the monsoon circulation).

[20] For the SHCI, the index from the reanalysis mostly lies within the range of our ensemble members shown in Figures 1d-1f. The variances of the ensemble means are slightly lower than for the $E A W M_{S L P}$ ensemble mean indices, indicating a weaker influence from the imposed forcing.
Overall the interannual correlations for the ensemble mean indices are lower than for the $E A W M_{S L P}$ index. In the case of CLIM-TROPICS the correlation is only marginally significant, suggesting now only a weak influence from the tropics. A higher correlation is found in OBS-TROPICS when the influence of extratropical SSTSI is included. The correlations between the indices from possible realisations and the index from the reanalysis (Figure 2b) show a similar result with an improvement when prescribing extratropical SSTSI. This indicates the importance of the variability of extratropical SSTSI for the SH. One possibility is that the variability of Arctic sea ice is influential on the SH. This is consistent with $W u$ et al. [2011] and also Petoukhov and Semenov [2010] who state that sea-ice coverage in the Barents-Kara Sea can influence the continental surface temperature across Eurasia. In the case of OBS-NO, the correlation between the ensemble mean index and the index from the reanalysis is not significant, with the implication that the influence of extratropical SSTSI is only revealed when correctly representing the tropics, as in OBS-TROPICS.

[21] Finally, we take a look at the linear trends of the $E A W M_{S L P}$ and the SHCI indices over the full 42 year period. The PDFs of possible linear trends in the different experiments have been compared with the trends from the reanalysis (not shown). The negative linear trend of the $E A W M_{S L P}$ in the reanalysis is $-0.25 \sigma / 10 \mathrm{y}$. This lies inside the $95 \%$ range of possible linear trends of both OBS-NO and OBS-TROPICS while it is outside the $99 \%$ range of possible trends in CLIMTROPICS. The mean of the PDF of trends of OBS-TROPICS is also shifted strongest $(-0.04 \sigma / 10 \mathrm{y}, 16 \%$ of the reanalysis trend) towards the negative EAWM trend. These results suggest a role for extratropical SSTSI on the trend in the $E A W M_{S L P}$ index.

[22] The linear trend $(-0.4 \sigma / 10 y)$ in the SHCI index from the reanalysis is particularly strong and is significantly 
different from zero at the 99\% level (assuming that each year is independent from the other). This trend lies outside the $99 \%$ range of possible trends of all experiments. The PDF of trends of OBS-TROPICS is, nevertheless, shifted the most towards the trend in the reanalysis. The mean of the trend distribution in this case is $20 \%$ of the reanalysis trend magnitude $(-0.08 \sigma / 10 \mathrm{y})$. OBS-NO $(-0.03 \sigma / 10 \mathrm{y})$ and CLIMTROPICS $(-0.05 \sigma / 10 \mathrm{y})$ show a weaker signal in the mean of possible linear trends. Overall, the evolution of the tropics in combination with the extratropical SSTSI anomalies appears to be the strongest influence on the trends in the $E A W M_{S L P}$ and SHCI indices according to our experiments.

\section{Summary and discussion}

[23] Although in the observations, the correlation between the $E A W M_{S L P}$ and NINO indices is weak (but still negative as found in other studies), our experiments suggest a strong influence of the tropical circulation on the interannual variability of the EAWM with at least $25 \%$ of the interannual variance of the $E A W M_{S L P}$ index captured by the ensemble mean index of the tropical relaxation experiments. Despite the possibility that our results may depend on both the model used for our study and the choice of indices we have analyzed [see Wang and Chen, 2010], this is in general agreement with the tropical influence found in previous observational studies [e.g., Li, 1990; Zhang et al., 1997] but also suggests that variability in the tropics other than ENSO is important for forcing the EAWM. The influence is probably mostly by circulation anomalies in the tropical Pacific and Indian Ocean sectors, a hypothesis not verifiable with our experiments and a possible field for further study. Nevertheless, with improved seasonal forecast skill in the tropics, our results suggest a corresponding enhanced predictability of the EAWM, consistent with recent results from $\mathrm{Li}$ and Wang [2012].

[24] Our experiments can only account for a small part of the weakening trends in the $E A W M_{S L P}$ index and the SHCI index during the analysis period. Nevertheless, extratropical SSTSI, combined with a proper representation of the tropics (OBS-TROPICS) appears as the strongest influence on the trend in our experiments. Since the global warming signal is part of the trend in both the tropics and extratropical SSTSI, it is possible that the trends seen in the $E A W M_{S L P}$ index and the SHCI index are in turn being influenced by global warming. It is also possible that including the changing anthropogenic radiative forcing in the model would have improved the model's ability to reproduce the trends.

[25] Acknowledgments. We are grateful to the ECMWF for the provision of the model and the use of computer facilities to carry out the model runs reported here. G.G. and R.J.G. have been supported by GEOMAR, Kiel. We are grateful to two anonymous reviewers for their helpful comments.

[26] The Editor thanks the two anonymous reviewers for their assistance in evaluating this manuscript.

\section{References}

Chan, J. C. L., and C. Li (2004), The East Asian winter monsoon, in East Asian Monsoon, pp. 54-106, World Sci., Singapore.
Copsey, D., R. Sutton, and J. R. Knight (2006), Recent trends in sea level pressure in the Indian Ocean region, Geophys. Res. Lett., 33, L19712, doi:10.1029/2006GL027175.

Gong, D.-Y., and C.-H. Ho (2002), The Siberian High and climate change over middle to high latitude Asia, Theor. Appl. Climatol., 72(1-2), 1-9, doi: $10.1007 / \mathrm{s} 007040200008$

Greatbatch, R. J., G. Gollan, T. Jung, and T. Kunz (2012), Factors influencing Northern Hemisphere winter mean atmospheric circulation anomalies during the period $1960 / 61$ to $2001 / 02, Q$. J. R. Meteorol. Soc., 72, 1-9, doi:10.1007/s007040200008.

Hori, M. E., and H. Ueda (2006), Impact of global warming on the East Asian winter monsoon as revealed by nine coupled atmosphere-ocean GCMs, Geophys. Res. Lett., 33, L03713, doi:10.1029/2005GL024961.

Hoskins, B., R. Fonseca, M. Blackburn, and T. Jung (2012), Relaxing the tropics to an 'observed' state: Analysis using a simple baroclinic model, Q. J. R. Meteorol. Soc., doi:10.1002/qj.1881, in press.

$\mathrm{Hu}, \mathrm{Z} . \mathrm{-Z}$. (1997), Interdecadal variability of summer climate over East Asia and its association with $500 \mathrm{hPa}$ height and global sea surface temperature, J. Geophys. Res., 102(D16), 19,403-19,412, doi:10.1029/97JD01052.

Jhun, J.-G., and E.-J. Lee (2004), A new East Asian winter monsoon index and associated characteristics of the winter monsoon, J. Clim., 17(4), 711-726, doi:10.1175/1520-0442(2004)017<0711:ANEAWM>2.0.CO;2.

Jung, T., M. J. Miller, and T. N. Palmer (2010), Diagnosing the origin of extended-range forecast errors, Mon. Weather Rev., 138(6), 2434-2446, doi:10.1175/2010MWR3255.1.

Li, C. (1990), Interaction between anomalous winter monsoon in East Asia and El Nino events, Adv. Atmos. Sci., 7(1), 36-46, doi:10.1007/ BF02919166.

Li, F., and H. J. Wang (2012), Predictability of the East Asian winter monsoon interannual variability as indicated by the DEMETER CGCMS Adv. Atmos. Sci., 29(3), 441-454, doi:10.1007/s00376-011-1115-3.

Petoukhov, V., and V. A. Semenov (2010), A link between reduced Barents-Kara sea ice and cold winter extremes over northern continents, J. Geophys. Res., 115, D21111, doi:10.1029/2009JD013568.

Trenberth, K., and J. Hurrell (1994), Decadal atmosphere-ocean variations in the Pacific, Clim. Dyn., 9(6), 303-319.

Trenberth, K. E., and D. P. Stepaniak (2001), Indices of El Niño evolution, J. Clim., 14(8), 1697-1701, doi:10.1175/1520-0442(2001)014<1697: $\mathrm{LIOENO}>2.0 . \mathrm{CO} ; 2$.

Trenberth, K. E., J. M. Caron, D. P. Stepaniak, and S. Worley (2002) Evolution of El Niño-Southern Oscillation and global atmospheric surface temperatures, J. Geophys. Res., 107(D8), 4065, doi:10.1029/ 2000JD000298.

Uppala, S. M., et al. (2005), The ERA-40 re-analysis, Q. J. R. Meteorol. Soc., 131(612), 2961-3012, doi:10.1256/qj.04.176.

Wang, B. (2006), The Asian Monsoon, 781 pp., Praxis, Chichester, U. K.

Wang, L., and W. Chen (2010), How well do existing indices measure the strength of the East Asian winter monsoon?, Adv. Atmos. Sci., 27(4), 855-870, doi:10.1007/s00376-009-9094-3.

Wang, L., W. Chen, and R. Huang (2008), Interdecadal modulation of PDO on the impact of ENSO on the East Asian winter monsoon, Geophys Res. Lett., 35, L20702, doi:10.1029/2008GL035287.

Wang, L., R. Huang, L. Gu, W. Chen, and L. Kang (2009), Interdecadal variations of the East Asian winter monsoon and their association with quasi-stationary planetary wave activity, J. Clim., 22(18), 4860-4872, doi:10.1175/2009JCLI2973.1.

Wu, B.-Y., J.-Z. Su, and R.-H. Zhang (2011), Effects of autumn-winter Arctic sea ice on winter Siberian High, Chin. Sci. Bull., 56(30), 3220-3228, doi:10.1007/s11434-011-4696-4.

Yang, S., K. Lau, and K. Kim (2002), Variations of the East Asian jet stream and Asian-Pacific-American winter climate anomalies, J. Clim. 15(3), 306-325, doi:10.1175/1520-0442(2002)015<0306:VOTEAJ $>2.0$. $\mathrm{CO} \cdot 2$

Zhang, C., and H. Zhang (2010), Potential impacts of East Asian winter monsoon on climate variability and predictability in the Australian summer monsoon region, Theor. Appl. Climatol., 101(1-2), 161-177, doi:10.1007/ s00704-009-0246-2

Zhang, Y., K. R. Sperber, and J. S. Boyle (1997), Climatology and interannual variation of the East Asian winter monsoon: Results from the 1979-95 NCEP/NCAR reanalysis, Mon. Weather Rev., 125(10), 2605-2619, doi:10.1175/1520-0493(1997) 125<2605.CAIVOT $>2.0 . \mathrm{CO} \cdot 2$

Zhou, T., R. Yu, H. Li, and B. Wang (2008), Ocean forcing to changes in global monsoon precipitation over the recent half-century, J. Clim. 21(15), 3833-3852, doi:10.1175/2008JCLI2067.1. 